\title{
Global prevention
}

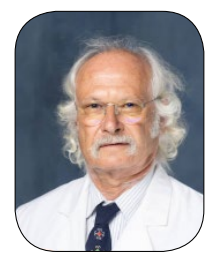

Jean-François ROULET

DDS, Habil, Prof hc, Dr hc, Professor

University of Florida, Gainesville, FL, USA

Stomatology Edu Journal

Founding Editor

Dear readers,

The year 2020 is over and it was completely dominated by the COVID-19 pandemic, which as we all know started on December $30^{\text {st }} 2019$ in Wuhan [1]. In our minds we look back at a very bad year with more than 1.8 million people that passed away due to the infection that may end up being utterly deadly, especially if individuals are exposed to additional risks. We were all faced with severe restrictions which have profoundly changed our lifestyles, from the obligation to wear masks and keep social distancing to skipping social gatherings, large events, and travelling. Altogether a bad year and a big crisis. However, in every crisis there is a chance as well. The positive thing is that the world population is now talking about prevention and is sensitized to everything that is prevention. Furthermore, we can widely see how people may react to preventive measures by either accepting them or rejecting them by hiding behind abstruse theories like claiming the pandemic is an illusion created by the mighty and powerful.

This brought me to the idea that we dentists that (I claim it for myself) have grown up with prevention should jump on the bandwagon of general prevention and based on our experience help to move general health up to a higher level. Wherever I look I see prevention and potential to increase its level with the corresponding knowledge. Prevention works best when it can be consumed without a special effort; examples here are the water fluoridation to reduce the incidence of caries or the reduction of saturated fats or the reduction of sugar in processed food to fight obesity. Looking at cars, ABS or airbags work according to the same principle. Prevention that requires the recipient's activity mainly boils down to a change in lifestyle, which is the most difficult task to accomplish. Here the input of psychologists is welcome as well as the one of legal experts when preventive measures should be backed with laws and enforced. We have seen during the corona year that this may be a big challenge. There were episodes where people were afraid to ask other people to wear a mask where it was mandatory, because they were afraid of violent reactions. Another example I remember were party goers that violated all requirements to wear masks and social distancing for a big new year's party that became so violent that the police quit dispersing the masses, or simply people attending discos that instead of giving their address just wrote down a bogus address to avoid contact tracing. A way of enforcement is controlling and fining violators. But it may be tricky to find the right way. I remember that many years ago, when wearing a seat belt in a car became mandatory, you could buy t-shirts with a seatbelt printed on them to avoid being pulled out of traffic and getting a ticket!

Today some cars offer the seatbelt once the person is seated or simply start with an ugly buzz a few seconds after the passenger is seated. To reduce the level of fatalities because of car accidents by defensive driving is much more difficult to enforce.

The overall conclusion is that we need to bundle all our expertise to improve prevention, since now the moment seems to be favorable. We must come out of our silos and think outside the box. In dentistry we train our students in the techniques of motivation, which is the very first step in changing people's behavior, and we have established simple measuring tools to monitor the progress of oral hygiene. In fighting infectious diseases vaccination has become the favorite tool, but we notice more and more people that do not let themselves or their kids to be vaccinated, with putting themselves and others at risk. Remember how many 
years it took to eradicate small pox or polio? It took a lot of measures to accomplish what required bundled knowledge in immunology, as well as information transfer, persuasion and logistics. Law makers may be required to do that when it comes to regulations. I know that in Denmark a "fat tax" was introduced with the idea to fight obesity. In Switzerland for the same reason, students were required to take more physical education classes.

To help with this process I have decided to create a webpage (www.globalprevention.ch) where every specialty interested in prevention can share their ideas and find partners for the common goal: make our lives and health better. Dear experts, make your knowledge, your success, but also your problems and challenges known to the others by sharing them on this website.

Furthermore, develop crazy ideas! What about stimulating the use of facemasks by design: incorporating pheromones makes the wearer feel good; or incentivize the use of tracing applications and social distancing by a reduction of health care insurance premiums (this may work for many preventive measures that require behavioral changes).

Or create immunization by aerosols at events that attract big masses, like concerts, festivals, sports competitions, or political rallies.

Take the chances and help to make this a better world!

Sincerely yours

J-F Roulet

Stomatology Edu Journal

Founding Editor

\section{REFERENCES}

1. Buckley C, Kirkpatrick DD, Quin A., Hernandez JC. 25 Days That Changed the World: How Covid-19 Slipped China's Grasp. New York Times Jan 6, 2021. 